\title{
Estimates Of Sea Scallop (Placopecten Magellanicus) Incidental Mortality From Photographic Multiple Before-After-Control-Impact Surveys
}

DM Ferraro

AC Trembanis

DC Mille

David Rudders

Virginia Institute of Marine Science

Follow this and additional works at: https://scholarworks.wm.edu/vimsarticles

Part of the Marine Biology Commons

\section{Recommended Citation}

Ferraro, DM; Trembanis, AC; Mille, DC; and Rudders, David, "Estimates Of Sea Scallop (Placopecten Magellanicus) Incidental Mortality From Photographic Multiple Before-After-Control-Impact Surveys" (2017). VIMS Articles. 300.

https://scholarworks.wm.edu/vimsarticles/300

This Article is brought to you for free and open access by the Virginia Institute of Marine Science at W\&M ScholarWorks. It has been accepted for inclusion in VIMS Articles by an authorized administrator of W\&M ScholarWorks. For more information, please contact scholarworks@wm.edu. 


\title{
ESTIMATES OF SEA SCALLOP (PLACOPECTEN MAGELLANICUS) INCIDENTAL MORTALITY FROM PHOTOGRAPHIC MULTIPLE BEFORE-AFTER-CONTROL-IMPACT SURVEYS
}

\author{
DANIELLE M. FERRARO, ${ }^{1}$ ARTHUR C. TREMBANIS, ${ }^{1 *}$ DOUGLAS C. MILLER ${ }^{1}$ \\ AND DAVID B. RUDDERS ${ }^{2}$ \\ ${ }^{1}$ Robotics Discovery Laboratories, School of Marine Science and Policy, University of Delaware, 700 \\ Pilottown Road, Lewes, DE 19958; ${ }^{2}$ College of William and Mary, Virginia Institute of Marine Science, \\ PO Box 1346, Gloucester Point, VA 23062
}

\begin{abstract}
After several decades of stock decline, the Atlantic sea scallop (Placopecten magellanicus) resource has rebounded to become one of the most valuable fisheries in the United States. The continued sustainability of this fishery is supported by catch limits determined by annual stock projection models. Incidental mortality is an important term in these projection models, but is historically difficult to measure. Current estimates are derived from field experiments that relied heavily on qualitative observations and as a result are based on limited data with low precision. To better quantify incidental mortality, a multiple before-after-control-impact experimental design was used to measure the effect of scallop dredging on the disposition of sea scallops that remain uncaptured on the seafloor following dredging. An autonomous underwater vehicle was used to collect color photographs and side-scan sonar images of the seafloor before and after controlled dredge treatments in the mid-Atlantic and Georges Bank regions. Approximately 170,000 photographs were annotated for instances of mortality. Dredge-induced incidental mortality of $2.5 \%$ and $8 \%$ was estimated for the mid-Atlantic Bight and Georges Bank sites, respectively, a difference that is likely attributable to the relatively harder substrate of the scallop habitat on Georges Bank that results in greater physical trauma to the uncaptured scallops. This study provides a quantitative estimate of incidental mortality using a noninvasive platform that offers precise mission navigation for repeated surveys. The spatial scale and distribution of the study sites are broad relative to past incidental mortality studies, and the substrate types at each are common in the sea scallop fishery. Estimated mortality rates are lower than the values currently used in fishery stock models and suggest the existing values are conservative, but likely appropriate estimates for management purposes.
\end{abstract}

KEY WORDS: sea scallops, Placopecten magellanicus, incidental mortality, dredging, autonomous underwater vehicle

\section{INTRODUCTION}

The Atlantic sea scallop Placopecten magellanicus (Gmelin, 1791) fishery along the coastal northwestern Atlantic Ocean is one of the most valuable single species fisheries in the United States, ranging in value from 300 million to over half a billion U.S. dollars annually over the last decade (NMFS 2008, 2009, 2010, 2011, 2012, 2013, 2014, 2015, 2016). The first scallop fishery management plan was enacted in 1982 following near crashes in the 1970s and has been modified numerous times since then. The plan implemented management measures including gear modifications, limitations of fishing effort, and rotational area management (Hart \& Rago 2006). Due in large part to these changes, overfishing has not occurred in the sea scallop fishery since 2003 (NEFSC 2004), and recent stock projections suggest a low likelihood of overfishing in the near future (NEFSC 2014).

To ensure the fishery remains sustainable, stock status is updated annually by assessing and modeling the stocks. Stocks are monitored in situ by a combination of sampling techniques that include survey dredges, drop cameras, and towed camera systems (Stokesbury 2002, Taylor et al. 2008, NEFSC 2014). To accurately describe the stock, assessment models must accommodate a suite of spatially explicit, fishery-dependent factors, including nonharvest fishing mortality. Nonharvest mortality consists of multiple pathways of events, including the scallops that are captured and subsequently released as discards.

*Corresponding author. E-mail: art@udel.edu DOI: $10.2983 / 035.036 .0310$
Discard mortality can be largely attributed to physical trauma and exposure to warmer water and air temperatures during capture and handling that surpass the $20^{\circ} \mathrm{C}-24^{\circ} \mathrm{C}$ lethal limit for scallops (Dickie 1958, Dickie \& Medcof 1963, Bremec et al. 2004). In addition to discard mortality, scallops in the dredge path may not be retained by the dredge, either passing through the ring or interring spaces or being passed over by the dredge. Defined as incidental mortality, this component of nonharvest mortality typically arises from injuries resulting from interaction with the gear (Caddy 1989).

The present study focuses on estimating the fraction of noncaptured scallops that suffer incidental mortality in the path of the dredge. These scallops can be directly compromised by the physical impact of the dredge by being crushed or buried in the sediments (Caddy 1973, Naidu 1988). Dumping of bycatch and scallop viscera may attract and increase scavenger populations (Britton \& Morton 1994), and localized fishing efforts can result in greater susceptibility to predators (Caddy 1973, Jenkins \& Brand 2001) and disease (McLoughlin et al. 1991). Even though many of these indirect factors may be difficult to quantify, incidental mortality is defined formally and included in stock projection models as

$$
F_{\mathrm{I}}=\frac{F_{\mathrm{L}} c(1-e)}{e},
$$

where $F_{\mathrm{L}}$ is the rate of landed fishing mortality, $c$ is the fraction of scallops that suffer mortality in the path of the dredge but are not caught (i.e., incidental mortality), and $e$ is the efficiency of the dredge. Presently, values of $c$ used in projection models are 
$10 \%$ on the soft substrates of the mid-Atlantic and $20 \%$ on the relatively harder substrates of some parts of Georges Bank in the waters of New England (NEFSC 2014). Incidental mortality (c) is an important term in assessment models for many commercially important marine species, especially when fishing mortality rates are high. Historically, this process is difficult to measure and as a result largely understudied (Myers et al. 2000, Broadhurst et al. 2006).

Few studies have attempted to directly quantify sea scallop incidental mortality, but it is generally considered to be low (Hart \& Rago 2006). Caddy (1973) estimated $c$ to be $15 \%-20 \%$ on a gravelly substrate in the Gulf of St. Lawrence, Canada, by observing tracks from single dredge tows from a manned submersible. A similar submersible-based study suggested dredgeinduced damage and mortality for uncaught scallops was less than $5 \%$ on sandy substrate in the mid-Atlantic (Murawski \& Serchuk 1989). These studies were limited by underwater visibility and the inability to spatially relate the observations to the dredged areas. Despite this, these two studies represent the primary empirical basis for incidental mortality estimates used in the sea scallop stock assessment (NEFSC 2014).

The use of unmanned vehicles for fisheries stock assessment is in early development, but autonomous underwater vehicles (AUV) are already well-suited tools for habitat mapping and benthic surveys (Armstrong et al. 2006, Grasmueck et al. 2006, Seiler et al. 2012). Equipped with digital and acoustic imagery payloads, untethered and unmanned vehicles can enable highresolution acoustic and optical research at depths too deep or hazardous for boat-mounted instruments or divers. Propelled autonomous vehicles are effective at surveying distances ranging from kilometers to tens of kilometers on the time scale of hours, allowing for relatively efficient data collection for maps of high spatial resolution. An internal inertial navigation system (INS) aided with a Doppler velocity $\log$ (DVL), such as the one on the AUV used in this study, can produce submeter positioning accuracies with drift rates on the order of $1 \mathrm{~m} / \mathrm{h}$ enabling high precision and repeatability in replicate surveys. Bottom tracking enables the AUV to maintain a constant altitude off the seafloor, which is desired in most benthic mapping studies (Lamarche et al. 2016). In addition, autonomous systems do not appear to startle fauna to the same degree as towed or dropped systems (Fernandes et al. 2000, 2003), which is important when attempting to observe environments in an undisturbed state. Recent examples include the use of integrated downward-facing cameras to measure the distribution and abundance of invasive benthic species (Forrest et al. 2012) and monitor benthic assemblages (Bewley et al. 2015). As a useful complement to digital imagery, high-resolution acoustic sonar imagery illuminates the texture of the seafloor, revealing sonar facies that elucidate bottom features and relative sediment types (Raineault et al. 2012, Rankey \& Doolittle 2012, Trembanis et al. 2017). In the sea scallop fishery, AUV-derived imagery has been used to quantify scallop abundance and distribution (Singh et al. 2014, Walker et al. 2016), shell height distributions (Singh et al. 2013), and visualize dredge scars (Walker et al. 2016).

In this study, an AUV was used to advance the understanding of sea scallop incidental mortality with a multiple beforeafter-control-impact (MBACI) experimental design, enabling the characterization of scallop beds before and after dredge impacts. Incidental mortality of sea scallops that remain on the seafloor immediately after dredging was quantified across soft and relatively hard bottom substrates with varying dredge intensities. Given the impact of fishing gear on benthic organisms is highly dependent on substrate (de Groot 1984, Collie et al. 1997, Link 2005), field experiments were conducted on the sandy substrates of the Elephant Trunk Closed Area (ETCA) and mixed sand and gravel substrates of the Nantucket Lightship Closed Area (NLCA), capturing two major bottom types traditionally fished by the sea scallop industry. The current management system has resulted in noticeable increases of scallop abundance, but to continue effectively implementing the management strategies, precise and up-to-date monitoring of all sources of fishing mortality is needed. The uncertainty associated with current estimates of incidental mortality has significant implications for projecting stocks and optimizing harvest strategies (Myers et al. 2000). The findings of this study aim to provide a more robust statistical basis for the values used by the fishery and to facilitate a discussion of whether the existing values should continue to be included in current stock assessment models.

\section{MATERIALS AND METHODS}

\section{Study Areas}

Experimental sites were chosen within the ETCA and NLCA, two rotational management areas closed to scallop dredging at the time of the study (Fig. 1). These areas were selected because they represent contrasting bottom types typically encountered by the fishery. Specific sites were selected based on recommendations and input from recent tow-dredge survey results and dialog with fisheries management scientists. The ETCA is a region of sandy substrate in the mid-Atlantic Bight about $60 \mathrm{~km}$ off the coast of Delaware. The NLCA is located in the greater Georges Bank region near the southeastern extent of the Nantucket Shoals, $60 \mathrm{~km}$ off of Nantucket Island, MA. The substrate is dominated by coarse sand and gravel with interspersed boulder piles and deposits, especially in the northern portion of the area where the study was conducted. Manual annotation of the substrate in the seafloor photographs taken during this study confirmed the intended bottom types were targeted. Virtually all of the photographs in the ETCA contained sand with shell hash overlaid in some areas, and the photographs in the NLCA contained mixed sand and gravel with patchy rocky regions. The surveys in the ETCA and NLCA were carried out from July 8 to 16,2014 , and July 8 to 14, 2015, respectively, scheduled so both experimental efforts occurred at the same time of year.

\section{Equipment}

The photographic imaging platform used was a Teledyne Gavia AUV. For this study, the modular AUV was in an optical and acoustic habitat mapping configuration consisting of (fore to aft) a nose cone camera, lithium ion battery module, Kearfott T-24 INS and DVL, command module with user-selectable 900/ $1,800 \mathrm{kHz}$ Marine Sonic side-scan sonar, and propulsion module (Fig. 2). While underway, the AUV collected simultaneous side-scan sonar and photographic images of the seafloor. It also continuously recorded vehicle state parameters such as vehicle location, altitude, depth, pitch, and roll. 


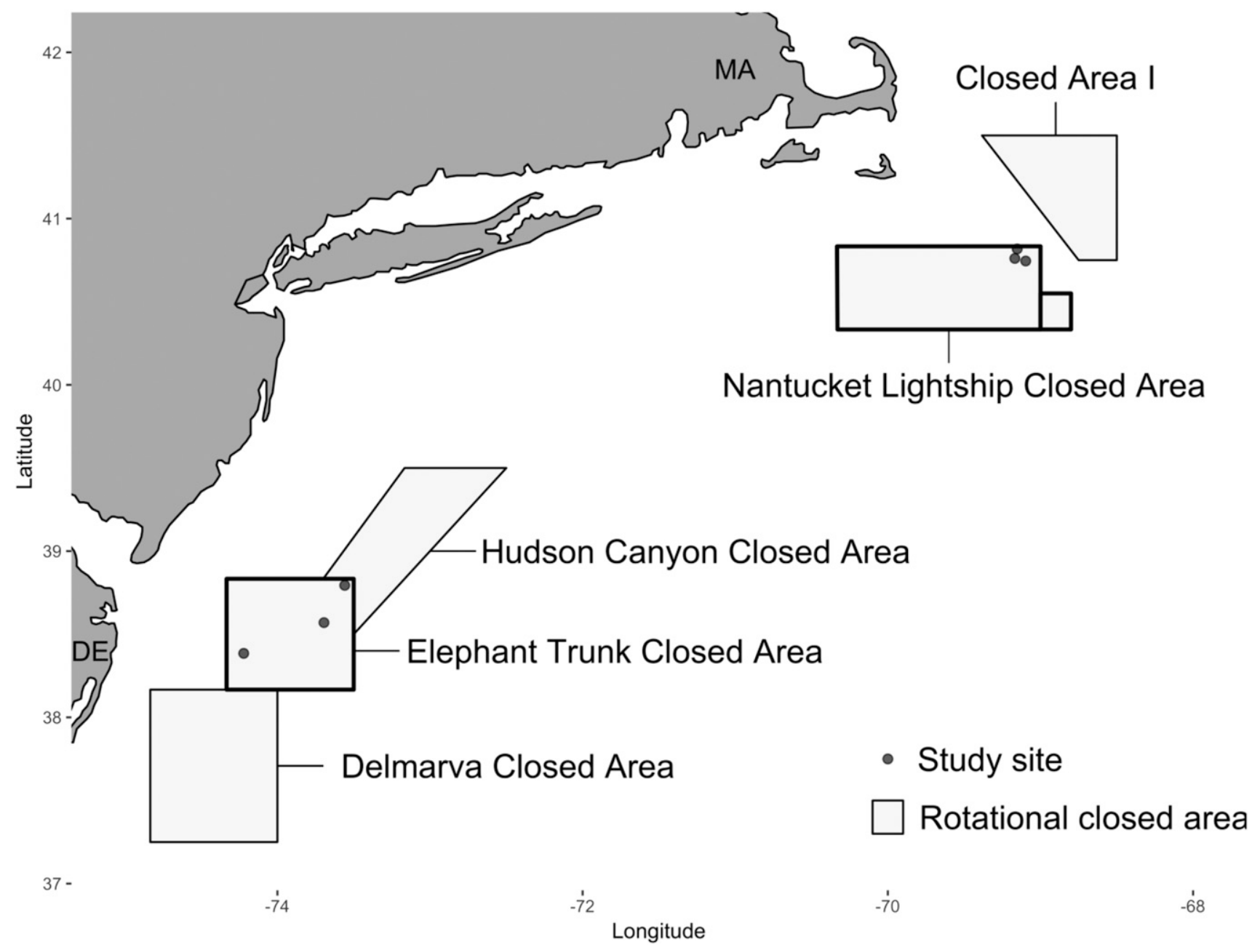

Figure 1. Map of rotational closed areas at the time of the study, highlighting the ETCA and NLCA where this study was conducted. The three replicate sites of experimental dredging are marked with circles.

The nose cone camera was a Point Grey Grasshopper 14S5C/M-C model with a Sony ICZ285AL CCD. The camera captured images at a resolution of $1,280 \times 960$ pixels with illumination provided by a synced light-emitting diode flash strobe mounted on the underside of the command module. All photographs were collected in portable pixmap format, a noncompressed
RGB image file type. The photographs were stored with embedded metadata including capture time and image location, as well as vehicle state parameters including AUV altitude, depth, pitch, and roll.

The camera has a Tanrom M23FM08 $8 \mathrm{~mm}$ focal length lens and a horizontal viewing angle of $41.19 \mathrm{deg}$ in seawater. During

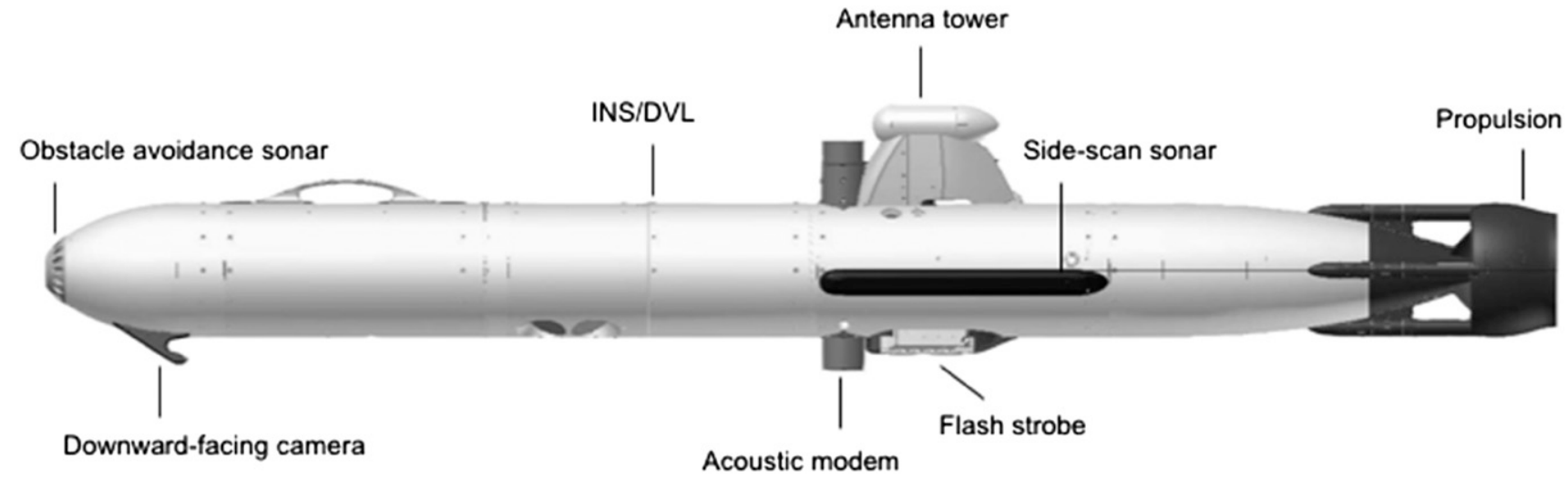

Figure 2. The University of Delaware Gavia AUV assembled for acoustic and optical mapping. 
all missions, the AUV was programmed to maintain a constant altitude of $2.5 \mathrm{~m}$ above the seafloor. The theoretical image width was calculated as

$$
W=2 H \tan \left(\frac{a_{\mathrm{h}}}{2}\right),
$$

where $W$ is image width in $\mathrm{m}, H$ is the height of the AUV from the seafloor in $\mathrm{m}$, and $a_{\mathrm{h}}$ is the horizontal viewing angle of the AUV, in degrees. This resulted in an average image footprint of $2.65 \mathrm{~m}^{2}$ at $2.5 \mathrm{~m}$ AUV altitude, where image width and height were 1.88 and $1.41 \mathrm{~m}$, respectively. The AUV platform was quite stable with regard to roll and pitch during the surveys, so these parameters were excluded from the image footprint calculations as they did not produce significant variation in image length or width. Average roll and pitch in the dataset were approximately 0.7 and $3.5 \mathrm{deg}$, respectively, resulting in less than $3 \%$ error in both dimensions. Other studies using the same AUV system also reported a similar error in image size without these parameters (Singh et al. 2013, 2014, Walker et al. 2016). These effects were considered negligible because this study did not examine shell height measurements that may have been affected by these contributing factors. Calibration of the camera system was conducted using the Camera Calibration Toolbox for Matlab developed by Bouguet (2004). The output of the toolbox produced a direct field of view measurement that confirmed the theoretical camera calculations aforementioned. In addition, the toolbox demonstrated that $68 \%$ of the image frame exhibited a distortion of less than four pixels or a maximum of $6 \mathrm{~mm}$ of ground distance at the observed AUV altitudes in this study. Although the camera calibration parameters can be used to correct sizing estimates of scallops, this distortion has no effect on counts of individual scallops annotated in this study.

The research platform was the F/V Christian and Alexa, a $30 \mathrm{~m}$ eastern-rigged scallop fishing vessel equipped with port and starboard New Bedford style dredges. All dredge treatments were carried out by the starboard dredge that was rigged in a way consistent with current gear regulations. In general, a New Bedford style sea scallop dredge is composed of a rigid, triangular frame with a $4.5 \mathrm{~m}$ wide cutting bar and ring bag knit with 4 inch $(10.16 \mathrm{~cm})$ linked rings, where the ring diameter is the primary mechanism of dredge size selectivity (Bourne 1964). Treatment tows were conducted at the standard commercial fishing speed of $2.0-2.5 \mathrm{~m} / \mathrm{s}$. After each individual tow, the catch was emptied on deck and sorted into bushels. One bushel of scallops was measured into $5 \mathrm{~mm}$ length bins as a representative sample of the total catch. After processing, all of the catch was discarded at a distance of at least one kilometer from the tow location to ensure the captured scallops were not returned to the AUV mission area.

\section{MBACI Experimental Design}

In before-after-control-impact (BACI) experiments, detection of the treatment effect is achieved by testing whether the difference in the desired parameter at a control site and an impacted site changes once the impact begins (Stewart-Oaten et al. 1986, Underwood 1993). To do so, selected areas of seabed were compared before and after a treatment (dredging), and the change at impacted areas was compared with that at control areas (no dredging). The specific BACI design used here is termed MBACI because there were multiple replicates in space (Downes et al. 2002). The BACI model incorporates the variability between replicate sampling locations over time (before $\times$ after) together with the change after the impact (control $\times$ impact) in the error term of the analysis. The impact is statistically significant when the variance due to the interaction between location and condition (impacted versus nonimpacted) is large compared with the variability at a location over time, plus residual error (Bernstein \& Zalinski 1983). Therefore, it is advantageous to reduce random error by choosing control and impact locations with similar environmental factors, including water depth, substrate type, and benthic assemblages (Smith et al. 1993, Collie et al. 1997). This criterion was satisfied by keeping the distance between control and impact treatments small and equidistant, yet sufficiently spaced to minimize the potential migration of individual scallops between treatment locations.

Replicate observations of scallop injury were made before and after treatments at both dredged and nondredged sites. Within each closed area, three sites were chosen that were distanced from each other by approximately $30-50 \mathrm{~km}$ in the ETCA and $6 \mathrm{~km}$ in the NLCA (Fig. 2). The sites within the ETCA were within a depth range of 50-60 m, and the sites within the NLCA were within a depth range of 60-70 m. Sites were chosen based on prior knowledge of scallop abundance from previous National Marine Fishery Service and Virginia Institute of Marine Science scallop surveys (D. Rudders, VA Institute of Marine Science, personal communication) and feasibility of dredging. Three treatments spatially separated by $500 \mathrm{~m}$ between each were designated within each site corresponding to the three dredge treatments: zero (control), one, or five tows. The one-tow and five-tow treatments were chosen to approximate relatively light and heavy dredging, and the zero-tow treatment represented the control. At a five-tow treatment, the five tows were intended to be made over the same track line to simulate a fishing area where many fishing vessels dredge simultaneously and have intersecting tracks (Walker et al. 2016). At each treatment, a "before" AUV mission was ran, a dredge treatment of one, five, or zero tows was conducted, and after the treatment the same AUV mission was ran again.

Autonomous underwater vehicle missions were of standard boustrophedon, or "lawnmower," design, composed of 10 parallel north to south lines of $750 \mathrm{~m}$ in length spaced apart by $2 \mathrm{~m}$ in a manner consistent with previous AUV-based scallop studies (Walker et al. 2016). The INS/DVL enabled precise underway navigation, with a total position drift rate of approximately $0.5 \mathrm{~m} / \mathrm{h}$ (Patterson et al. 2008), or $0.1 \%$ of distance traveled (Rankey \& Doolittle 2012, Trembanis et al. 2017). In this study, vehicle-estimated positioning between track lines of replicate missions varied at submeter precision based on digitization of repeatedly imaged acoustic targets registered in the side-scan sonar. For the purposes of this study, it is this precise repeatability of missions and not absolute positioning accuracy that is of critical importance. The terrain-following capability of the AUV was used to command a constant altitude of $2.5 \mathrm{~m}$. Vehicle state logs showed very little spread in altitude within a single mission or over a pair of replicate missions. Altitude varied within $7-8 \mathrm{~cm}$ of the commanded altitude over the duration of a single mission, and the means of replicate missions varied by about $1 \mathrm{~cm}$. With an image footprint of approximately $2.65 \mathrm{~m}^{2}$, this ensured overlap between sequential 
photographs as well as between lines to result in near $100 \%$ photographic coverage of the $13,500 \mathrm{~m}^{2}$ area of seafloor per mission. Sequential images overlapped by approximately $45 \%$, depending on the effect of bottom currents on the AUV's fixed propulsion setting of $600 \mathrm{rpm}$. During the second field season in the NLCA, lines were shortened to $550 \mathrm{~m}$ and increased in number to 14 to provide the ship operators a wider swath area target in which to center their dredge tow. During all AUV missions, the downward-facing camera collected photographs at an effective rate of $1.9 \mathrm{fps}$, and the $1,800 \mathrm{kHz}$ high-frequency side-scan sonar acoustically imaged the seabed simultaneously.

After the initial AUV survey, one, five, or zero (control) dredge tows were made through the center of the AUV-mapped region. The north to south orientation of the tows through the mapped region, also oriented north to south, helped ship operators dredge consistent and accurate tow paths. Control treatments were located between the one-tow and five-tow treatments, spatially separating the two dredged areas to minimize crossover effects. Dredging began approximately $0.5 \mathrm{~km}$ before reaching the treatment box to maintain a constant speed of $2.0-2.5 \mathrm{~m} / \mathrm{s}$ through the treatment area. The dredge catch was sorted on deck and discarded off-site several kilometers from the experimental domain. Immediately after the dredge treatment, the same AUV mission was repeated. The follow-up survey was executed as soon as possible after dredging while also allowing time for settling of disturbed sediments and onset of incidental mortality effects, on average $8 \mathrm{~h}$ posttreatment.

\section{Image Processing and Annotation}

All images collected by the AUV were first enhanced and then annotated using a custom online system. Most raw images were dark, so one of two enhancement schemes was used to clarify the contents of the photographs. Depending on the starting clarity of the photograph, either the Stretch Contrast plugin for GNU Image Manipulation Program (Quintero 1996) or Fred's ImageMagick Scripts retinex enhancement algorithm (Weinhaus 2007) was applied.

All enhanced images were incorporated into a custom online image annotation system that displayed the images in a clickdriven graphical user interface. Each photograph was viewed sequentially by AUV mission, and a trained image annotator identified each scallop in the photograph, as well as designating each scallop counted as "healthy" or "compromised." A "healthy" scallop was operationally defined as an apparently alive individual that lacked evidence of damage. Conversely, a "compromised" scallop was defined as an individual that was disarticulated, inverted, or otherwise displayed visible damage. Annotators could also select "unsure" to denote scallops with an unresolvable or uncertain health status, but only 147 scallops $(<0.06 \%)$ were annotated as such, making the proportion negligible within the complete AUV mission photoset. Several image-scale characteristics were also recorded, including presence or absence of scallops, seabed type (i.e., sandy, shell hash, gravel, or rocky), and image clarity. All annotations were stored in a MySQL relational database with associated image and AUV mission metadata.

To designate a healthy scallop, annotators identified individuals with nondamaged shells and hinges. In this case, the white left valve of scallops was flush to the seafloor, often within a slight depression in the seabed, and the orange or brown right valve faced into the water column. Mantle tissue was sometimes discernible on the shell margin. Often, a crescent-shaped shadow, cast by a scallop with valves normally open for feeding, could be seen near the margin. Compromised or damaged scallops were distinguished from live, healthy scallops as a shell fitting one of the health indicator groups potentially leading to mortality (Fig. 3) (Medcof \& Bourne 1964). The compromised scallops often possessed disarticulated shells and were whitish because of pigment loss. Scallops that were severely damaged at the hinge or had large holes or breaks through the middle of either the right or left valve were also noted as compromised. In addition, inverted scallops were marked as compromised. Dredging is likely to cause inversion and may leave the animal stressed and unable to normally right itself, potentially increasing vulnerability to predation (Caddy 1989, Minchin et al. 2000). Because $5 \%-10 \%$ of sea scallops are albino and have white right valves (D. Hart, Northeast Fisheries Science Center, personal communication), righted albino scallops were differentiated from inverted scallops by the presence of biological growth on the right valve exposed to the water column. For the purposes of this study, all compromised scallops were considered to be individuals contributing to incidental mortality, which may have biased incidental mortality values slightly high. The resolution of the AUV camera only illuminated the most obvious and severe damage, however, and minor injuries such as small cracks or chips that may not lead to mortality were not easily as resolved. In addition, scallops were only surveyed once $8 \mathrm{~h}$ after dredging, excluding individuals whose mortality may be delayed.

Fifteen annotators were trained to accurately identify scallops in photographs and assign each individual a healthy or compromised rating. Following training, each annotator was required to annotate a test set of 60 photographs and count within $5 \%$ of the approved correct number of total scallops
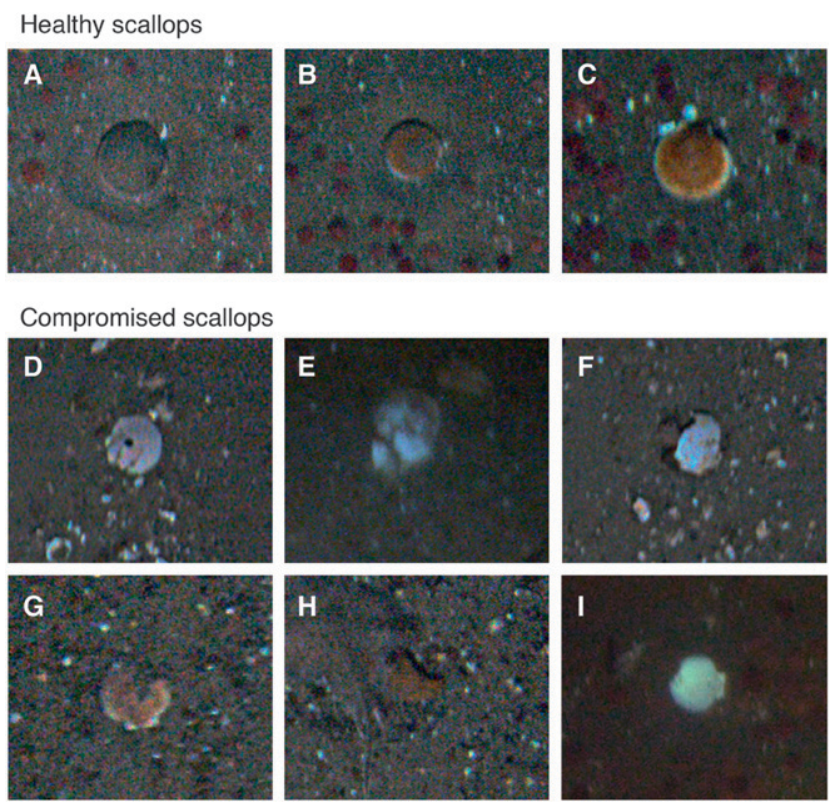

Figure 3. Examples of healthy, undamaged scallops (A-C), and damaged scallops from the project imagery database. Annotations of compromised scallops included individuals that were punctured (D), crushed (E), broken (F-H), or inverted (I). 
( $n=148)$ and proportion of compromised scallops. Further training and a second test set was assigned if an annotator did not fall within those bounds. Annotator error was approximated by the annotation of a larger subset of 928 photographs ( $n=988$ scallops) by all annotators. The standard deviation of the percent compromised scallops in the subset was $2.3 \%$ between annotators. Guidelines for annotation were as follows:

(1) Every scallop will be annotated (counted) and given a healthy, compromised, or unsure rating.

(2) A scallop will only be annotated if it is over $50 \%$ within the image frame.

(3) Empty shells will not be annotated.

(4) Every photograph will be annotated with the presence or absence of scallops within the image frame.

(5) Every photograph will be annotated with the dominant substrate as well as a qualitative indicator of image quality.

At ETCA Sites 1 and 2, 100\% of the image set was annotated. Images from ETCA Site 3 and all NLCA sites were downsampled to one of every four photographs to reduce the time spent annotating. Because photographs collected at $1.9 \mathrm{fps}$ had sufficient overlap, downsampling to $25 \%$ of the total images still preserved $57 \%$ of the total area imaged.

\section{Side-Scan Sonar Processing}

Raw side-scan sonar files were combined into mosaics with a ground resolution of $25 \mathrm{~cm}$ per pixel by removing the water column and applying slant range and beam angle correction in SonarWiz 6 (Chesapeake Technology Inc., Mountain View, CA). The resulting georeferenced mosaics created from postdredge missions were visually searched for dredge scars. Scars were detected by looking for a linear path roughly $4.5 \mathrm{~m}$ wide, smoother than the surrounding seabed, and lacking the pockmark features formed by scallops settling into the seabed. The dredge often created sharply defined linear trails of mounded sediment on the peripheral edges of the tow path. In addition, the predredge mission side-scan sonar files were processed and viewed side by side with postdredge mosaics to more easily distinguish dredge scars (Fig. 4). When scars were located, the bounds were manually digitized using the GIS polyline feature tool in Sonarwiz. Where five-tow treatments were applied, one or two digitizations were drawn around separate areas of intersecting scar paths to capture the dredged area without including the area outside of the scar. The scar bounds were used to constrain incidental mortality calculations to just the photographs taken within the path of the dredge.

Calculating incidental mortality within the dredge path removed some of the bias downward that may have been caused by the relatively high abundance of photographs annotated in each AUV mission but not actually within the visible dredge path, thus receiving no experimental treatment. On average, only $17 \%$ of the total AUV mission area was dredged during a one-tow treatment ( $83 \%$ untreated), and $56 \%$ of the mission area was dredged during a five-tow treatment (44\% untreated). Incidental mortality values calculated over the entire AUV mission tended to be smaller, likely because of the noise introduced by the larger set of photographs that included a large proportion of photographs outside of the dredge path. The hypothesis that scallops displaced outside of the dredge path by the dredge do not contribute significantly to incidental mortality was tested by adding a $3 \mathrm{~m}$ buffer area around the dredge scar. In fact, the addition of the buffer slightly reduced the proportion of compromised scallops observed after dredging, suggesting scallops that fall just outside of the dredge path do not contribute significantly to incidental mortality.

\section{Incidental Mortality Calculation}

Mortality values were calculated from the fraction of photographs in each mission that were within the path of the dredge. A photograph was defined as being within the dredge path if its centroid location fell within the scar bounds. Incidental fishing mortality for each before-after AUV mission pair was defined as

$$
c=\left(\frac{\text { compromised }_{\mathrm{t}}}{\text { total }_{\mathrm{t}}}-\frac{\text { compromised }_{0}}{\text { total }_{0}}\right) \times 100,
$$

where compromised $t_{t}$ and compromised ${ }_{0}$ are the numbers of compromised scallops at time $t$ (after dredging) and time 0 (before dredging), respectively, and total $t_{t}$ and total $l_{0}$ are the numbers of total scallops at time $t$ and time 0 , respectively. Scallops with health annotations of "unsure" constituted less than $0.06 \%$ of the total $(n=147)$ and were removed from the dataset before analysis.

\section{Statistical Analysis}

A restricted maximum likelihood linear mixed effects model was fit to the data. The model was constructed in $\mathrm{R}$ statistical software (R Core Team 2016) using the lme4 package (Bates et al. 2015) as

$$
\begin{aligned}
\% \text { Compromised } & \sim \text { Treatment }+ \text { Period }+ \text { Treatment } \\
& \times \text { Period }+(1 \mid \text { Site }),
\end{aligned}
$$

where \% Compromised represented the outcome variable, percent compromised scallops. Explanatory variables were Treatment, representing the effect of the one- or five-tow dredge treatments, Period, representing the effect of the interval between the before and after surveys, Treatment $\times$ Period, representing the interaction term, and (1|Site) representing the random site effect. To investigate the effects of the two dredge treatments on any difference in incidental mortality between the replicate sites, two factor analyses of variance (ANOVA) were performed on the data.

\section{RESULTS}

In the ETCA, a total of 81,536 scallops were annotated for instances of mortality (Table 1). Incidental mortality values were low overall for all dredge treatments, reaching a maximum of $5.61 \%$ after a one-tow treatment (Fig. 5). Following the one-tow treatments, mean change in percent compromised scallops was $0.66 \% \pm 2.45 \%$ (se). Incidental mortality after the five-tow treatments was still low but marginally higher than the one-tow treatments with a mean change in compromised scallops of $2.46 \%$ $\pm 2.16 \%$. The three control treatments showed little change posttreatment as anticipated, with a mean change in compromised scallops of $-0.28 \% \pm 0.22 \%$. Standard errors of the means were relatively high because of the relatively high intratreatment variability (Table 2). A two factor ANOVA on the data fit to a linear mixed effects model showed no significant difference in mortality as a result of one or five dredge tows. 
Images from the NLCA were downsampled to one in every four photographs, resulting in a subset of $57 \%$ of the original seafloor area photographed and the annotation of 61,685 total scallops (Table 1). Overall incidental mortality values were slightly higher than in the ETCA, but had larger spread within treatments (Fig. 5). The maximum percent compromised
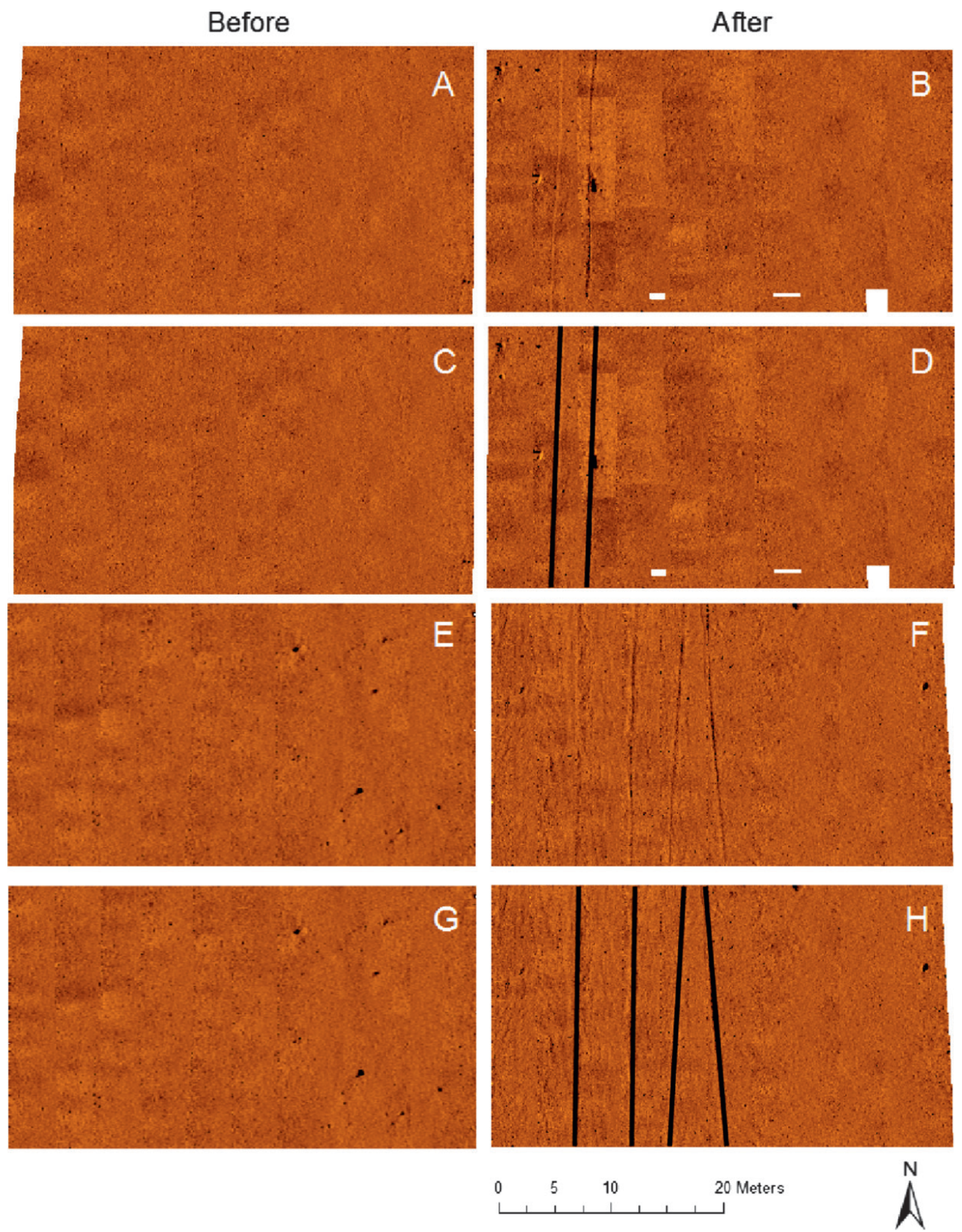

Figure 4. Example side-scan sonar mosaics with and without guides before and immediately after one dredge tow (A-D), and before and immediately after five dredge tows (E-H) at Sites 2 and 1 in the NLCA, respectively. One-tow treatments were distinguishable by a single dredge scar parallel to the and within the AUV mission path (D), whereas five-tow treatments were distinguishable by a group of overlapping dredge scars parallel and/or subparallel to and within the AUV mission path $(\mathrm{H})$. 
TABLE 1.

Number of healthy, compromised, and total scallops counted in AUV photographs within the dredge path before and after zero, one, and five tow treatments.

\begin{tabular}{|c|c|c|c|c|}
\hline Site & Treatment & Number of scallops & Number of healthy & Number of compromised \\
\hline \multirow[t]{6}{*}{ ETCA 1} & 0 tows before & 8,010 & 7,670 & 337 \\
\hline & 0 tows after & 8,941 & 8,569 & 369 \\
\hline & 1 tow before & 1,677 & 1,571 & 105 \\
\hline & 1 tow after & 852 & 821 & 30 \\
\hline & 5 tows before & 11,532 & 11,438 & 86 \\
\hline & 5 tows after & 7,970 & 7,631 & 333 \\
\hline \multirow[t]{6}{*}{ ETCA 2} & 0 tows before & 7,009 & 6,710 & 293 \\
\hline & 0 tows after & 7,702 & 7,436 & 266 \\
\hline & 1 tow before & 2,824 & 2,720 & 94 \\
\hline & 1 tow after & 2,729 & 2,656 & 72 \\
\hline & 5 tows before & 7,191 & 6,964 & 224 \\
\hline & 5 tows after & 1,994 & 1,816 & 174 \\
\hline \multirow[t]{6}{*}{ ETCA 3} & 0 tows before & 4,245 & 4,219 & 26 \\
\hline & 0 tows after & 4,878 & 4,850 & 28 \\
\hline & 1 tow before & 534 & 527 & 6 \\
\hline & 1 tow after & 383 & 357 & 25 \\
\hline & 5 tows before & 2,532 & 2,385 & 147 \\
\hline & 5 tows after & 533 & 509 & 22 \\
\hline Total & & 81,536 & 78,849 & 2,637 \\
\hline \multirow[t]{6}{*}{ NLCA 1} & 0 tows before & 978 & 777 & 200 \\
\hline & 0 tows after & 823 & 626 & 196 \\
\hline & 1 tow before & 553 & 538 & 15 \\
\hline & 1 tow after & 397 & 377 & 20 \\
\hline & 5 tows before & 2,595 & 2,505 & 84 \\
\hline & 5 tows after & 1,303 & 1,072 & 231 \\
\hline \multirow[t]{6}{*}{ NLCA 2} & 0 tows before & 4,613 & 4,362 & 247 \\
\hline & 0 tows after & 4,849 & 4,624 & 224 \\
\hline & 1 tow before & 696 & 618 & 76 \\
\hline & 1 tow after & 553 & 544 & 9 \\
\hline & 5 tows before & 1,392 & 1,346 & 44 \\
\hline & 5 tows after & 1,305 & 1,154 & 151 \\
\hline \multirow[t]{6}{*}{ NLCA 3} & 0 tows before & 9,420 & 9,014 & 400 \\
\hline & 0 tows after & 11,711 & 11,224 & 486 \\
\hline & 1 tow before & 868 & 814 & 53 \\
\hline & 1 tow after & 876 & 793 & 83 \\
\hline & 5 tows before & 8,250 & 7,841 & 405 \\
\hline & 5 tows after & 10,433 & 9,820 & 604 \\
\hline Total & & 61,615 & 58,049 & 3,528 \\
\hline
\end{tabular}

Three sites each were located within the ETCA and NLCA.

scallops observed after dredging was $14.49 \%$, after a five-tow treatment. At the one-tow treatments, mean change in percent compromised scallops was $-1.20 \% \pm 4.06 \%$. This was skewed negatively because of an outlier at Site 2 , where an apparent $9.29 \%$ decrease in compromised scallops following dredging was observed. This may be attributed to a relatively small sample size at that particular treatment because only $11 \%$ of the mapped area was within the dredge scar. Only 696 scallops were found in the dredge path before dredging and 553 scallops were found after, with just nine annotated as compromised following the dredge treatment (Table 1). Sites 2 and 3 had more predictable results after the one-tow treatment, with increases of $2.33 \%$ and $3.37 \%$, respectively. At the five-tow treatments, incidental mortality was $7.93 \% \pm 3.94 \%$. The five-tow treatments in the NLCA had substantially higher incidental mortality than those of the ETCA, particularly at Site 3 where an increase in percent compromised scallops of nearly $15 \%$ was observed (Table 2 ). The three control sites had a mean change of $0.84 \% \pm 1.27 \%$ and had a larger SE than the mean change of the control sites at the ETCA. A two factor ANOVA on the data fit to a linear mixed effects model showed no significant difference as a result of either treatment.

\section{DISCUSSION}

The estimates of incidental mortality for sea scallops left on the seafloor after dredging are slightly lower than but generally corroborate the values currently used in fishery assessment models. The five-tow treatments were considered approximately representative of real "to-depletion" scallop dredging, and those incidental mortality values were compared with those used in the fishery and found in the literature (Table 3). In addition, the maximum incidental mortality values found from 


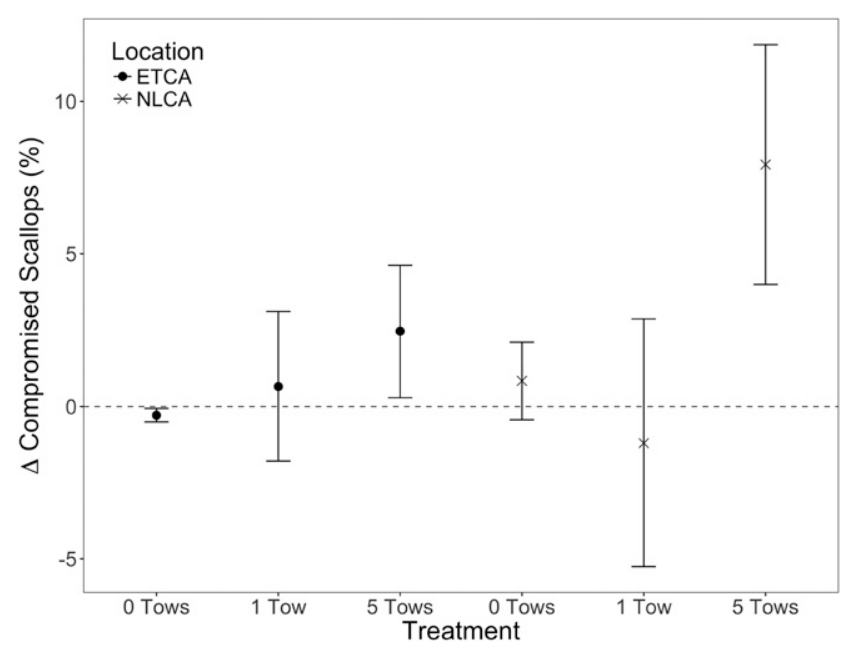

Figure 5. Mean change in percent compromised scallops within the dredge path following one, five, or zero tows in the ETCA and the NLCA. The dotted line at 0 represents where these data should fall if there were no treatment effect. Error bars represent the SEM $(n=3)$.

any treatment, considered the worst-case scenario, were also compared with existing values. Although not representative of the entire dataset, the maximum values aligned well with those in previous studies. In the ETCA, a maximum increase in compromised scallops of $5.61 \%$ was observed, complementing the previous estimations of Murawski and Serchuk (1989) of up to $5 \%$ mortality on sandy substrate in the mid-Atlantic. The mean value of the five-tow treatments, $2.46 \%$, matches the evidence that suggests the level of incidental mortality in sea scallops is relatively small (Hart \& Rago 2006). The fishery currently uses $10 \%$ for the proportion of incidental mortality on sandy substrates, which is slightly higher than the value observed in this study in the ETCA. It may be practical to use precaution with moderately uncertain parameters, such as incidental mortality, to avoid overfishing resulting from misspecification of reference points (Hart 2013).

In the NLCA, a maximum incidental mortality value of $14.19 \%$ was observed. This approaches the lower bounds of the $15 \%-20 \%$ range estimated by Caddy (1973) on a gravel substrate significantly north of Georges Bank, in the Gulf of St. Lawrence, Canada. The substrate observed at the NLCA contained less gravel, rocks, and large boulders than what was described by Caddy (1973), suggesting the incidental mortality estimates in this study may be smaller because of the relatively smoother substrate at the study sites. In the NLCA, the substrate in greater than $84 \%$ of photographs was assessed by annotators as mostly sand, so it is reasonable to believe more damage may have been observed if gravel and rocks made up a higher proportion of the substrate. The mean value of the fivetow treatments was $7.93 \%$, again supporting the evidence that scallop incidental mortality is likely to be low overall (Hart \& Rago 2006). Assessment models currently use $20 \%$ to represent incidental mortality on designated hard substrate areas. Again, this model value is higher than those in this study and in the literature, but it is a reasonable conservative estimate for this parameter particularly on a hard substrate that is likely to result in higher levels of damage as a result of interaction with the dredge (Murawski \& Serchuk 1989). Sampling in two closed areas known to have sandy and moderately hard substrates, respectively, enabled the comparison of dredge impact between contrasting substrate compositions. Higher values of incidental mortality were observed in the NLCA relative to the ETCA. Results suggest incidental mortality was higher in the NLCA, especially at the five-tow treatments, where an increase in the amount of compromised scallops was seen at all three replicate sites and was the sole example of such in the entire dataset. These results support previous hypotheses that dredging on hard substrate may lead to scallops being crushed between the dredge and dislodged rocks (Murawski \& Serchuk 1989).

This study used dredge treatments of relatively light and heavy dredging intensity to better understand the compounding effect repeated dredge tows may have on incidental mortality, particularly in the context of a heavily fished area. Vining (1978) acknowledged that seabed disturbance as a result of mobile benthic fishing gear is highly variable as some parts of the seafloor may be fished a single time, whereas others are fished multiple times by one or several vessels. Although effort was made to control for this during five-tow treatments by dredging over the same path each time, the tows diverged or intersected multiple times, consistent with other observations of commercial fishing efforts in open areas (Walker 2013). As a result, the five-tow treatments are not necessarily five times the intensity of a single tow, but may fall anywhere on the spectrum of one to five tows. Higher values of incidental mortality were observed following the five-tow treatments regardless of the variability in spatial overlap, particularly in the NLCA. Therefore, it is likely that many scallops interacted with the gear several times throughout the duration of the treatment, especially because the efficiency of New Bedford style dredges is estimated to be $43 \%-54 \%$ (Gedamke et al. 2004, 2005). No observable change was detected in the number of compromised scallops following

TABLE 2.

Percent change in compromised scallops within the dredge path following treatments in the ETCA and NLCA.

\begin{tabular}{|c|c|c|c|c|c|c|}
\hline \multirow[b]{2}{*}{ Site } & \multicolumn{2}{|c|}{0 tows } & \multicolumn{2}{|c|}{1 tow } & \multicolumn{2}{|c|}{5 tows } \\
\hline & ETCA & NLCA & ETCA & NLCA & ETCA & NLCA \\
\hline 1 & -0.08 & 3.37 & -2.74 & 2.33 & 3.43 & 14.49 \\
\hline 2 & -0.73 & -0.73 & -0.69 & -9.29 & 5.61 & 8.41 \\
\hline 3 & -0.04 & -0.10 & 5.40 & 3.37 & -1.68 & 0.88 \\
\hline Mean & $-0.28 \pm 0.22$ & $0.84 \pm 1.27$ & $0.66 \pm 2.45$ & $-1.20 \pm 4.06$ & $2.46 \pm 2.16$ & $7.93 \pm 3.94$ \\
\hline
\end{tabular}

Uncertainty reported as SEM. 
TABLE 3.

Comparison of the maximum and mean percent of scallops suffering incidental mortality $(c)$ within the dredge path across sandy and hard bottom substrates found in this study (indicated with *) to those in the literature and used currently in the fishery management model.

\begin{tabular}{lcc}
\hline \hline & Sandy & Hard \\
\hline Fishery model & $10 \%$ & $20 \%$ \\
Literature & $<5 \%$ (Murawski \& & $15 \%-20 \%$ \\
& Serchuk 1989) & $($ Caddy 1973$)$ \\
Mean (5-Tow)* & $2.46 \% \pm 2.16 \%$ & $7.93 \% \pm 3.94 \%$ \\
Maximum* & $5.61 \%$ & $14.19 \%$ \\
\hline
\end{tabular}

Uncertainty reported for five-tow treatment as the SEM.

the one-tow treatments, which suggests that a single tow may not be sufficient for this method or that the treatment effect is too small to detect with a sample size of three.

In this study, substantial variability between sites hampered the detection of significant treatment effects. Three replicate sites were designated within each closed area to assess differences between the experimental dredging and control treatments. Incidental mortality differed substantially between sites at a given impact level, suggesting that the variance between sites located kilometers to tens of kilometers apart was larger than the variance because of the dredge treatment. Therefore, it is reasonable that a modest and variable incidental mortality effect would be difficult to detect given small sample sizes of only three sites. More replicate sites may have reduced the uncertainty around the estimate, but with a low sample size, a statistically significant difference was not detected. In addition, an order of magnitude difference in scallop abundance between treatment sites was occasionally observed (Table 1). An average of less than 200 compromised scallops was observed in the annotated photographs before and after dredging at both the ETCA and NLCA, and in some cases fewer than 100, further challenging the detection of a small and variable treatment effect and widening the confidence interval of the estimates.

The scale of the incidental mortality point estimates and the novel method established here to estimate incidental mortality were of primary interest for this study. The AUV used in this study has been previously demonstrated to serve as an efficient acoustic and digital imaging platform (Walker 2013, Singh et al. 2014, Walker et al. 2016). The vehicle collected large numbers of photographs $(>10,000)$ over the duration of a single mission, resulting in image coverage of $13,500 \mathrm{~m}^{2}$ on each track line of $7.5 \mathrm{~km}$. Using this technology, existing incidental mortality survey scales (i.e., Caddy 1973, Murawski \& Serchuk 1989) were expanded from approximately $1 \mathrm{~km}$ long transects to track lines of several kilometers over an area of tens of thousands of square meters, resulting in at least a 5-fold increase of ground coverage and scallop counts from which to derive incidental mortality statistics. The highly precise navigation of the AUV enabled repeated surveys of an area, which was integral when targeting the same swath of substrate before and after a dredge treatment. The value of seafloor images was also improved relative to past studies as a result of precise georeferencing and subsequent spatial relation to the dredge path that was not possible in previous manned submersible studies. Side-scan sonar imaging captured the spatial extent of the dredge tows within a meter of positioning error. By contrast, Caddy (1973) and Murawski and Serchuk (1989) relied on deploying lead rope or acoustic beacons in the dredge path for divers to locate it later, as well as to distinguish it from other dredge tow paths left by active fishing boats. The combination of side-scan sonar and georeferenced photographs in this study was used to determine if a photograph, as well as the scallops it contained, was located inside or outside of the dredge path with high precision.

The calculation of fishing mortality rates, which include incidental mortality, has wide implications for the determination of sustainable fishing effort and subsequent fishery yield (Hart 2003). Although the results of this work did not suggest current fishing mortality models should be modified, a lower assumed level of incidental mortality has the potential to increase landings, at least for the first year after the change. The increase in landings because of a lower assumed incidental mortality can be approximated by

$$
\Delta L=B_{\mathrm{e}}\left(F_{\mathrm{L}}-F_{\mathrm{L}_{\text {new }}}\right),
$$

where $\Delta L$ is the change in landings in mt meats, $B_{\mathrm{e}}$ is the biomass of scallops of exploitable sizes in mt meats, $F_{\mathrm{L}}$ is the mean landed fishing mortality over exploitable sizes, and $F_{\mathrm{L}_{\text {new }}}$ is $F_{\mathrm{L}}$ recalculated with the incidental mortality values in this study. Using $B_{\mathrm{e}}=46,101 \mathrm{mt}$ meats and $F_{\mathrm{L}}=0.39$ for the mid-Atlantic, and $B_{\mathrm{e}}=29,533 \mathrm{mt}$ meats and $F_{\mathrm{L}}=0.54$ for open Georges Banks regions (NEFSC 2014), landings for the first year following could be theoretically increased by about $1,569 \mathrm{mt}$ meats. With a nominal ex-vessel price of 12 U.S. dollars per pound (NMFS 2016), this could amount to 41,513,400 USD. Increasing landings would probably decrease biomass for the subsequent year, however, offsetting the increase in landings from increased fishing mortality. In general, if fishing mortality is close to fishing mortality at maximum sustainable yield, reducing assumed levels of incidental mortality may increase landings the following year, but would only slightly affect longterm landings (Hart 2003).

This study provided estimates of sea scallop incidental mortality that support the values currently used by fishery managers. The findings suggest that dredging may result in the average loss of $8 \%$ and as high as $15 \%$ of the scallops that interact with the dredge but are not harvested, depending on the composition of the substrate. Because the study was carried out on the mid-Atlantic and Georges Bank fishing grounds with nested sites spaced kilometers to tens of kilometers apart, these results are representative of the spatial scale of the fishery. The AUV platform reduced some of the common sources of uncertainty in past calculations of incidental mortality, such as the inability to determine whether photographs were taken inside or outside of the dredge scar, but reaffirmed the need for automated image segmentation processes in the age of big data (Gallagher 2014). This work has demonstrated that an AUV can successfully capture organism damage in photographs and lays the foundations for future investigations of scallop incidental mortality. Specifically, this dataset can be processed further to relate shell height to mortality since New Bedford style dredges have specific sizeselectivity curves (Yochum \& Dupaul 2008) and because small 
scallops may avoid gear by swimming (Caddy 1968). It could also be mined for abundances of scallop predators to contribute to existing knowledge about postdredging predator aggregations (Caddy 1968, 1973, Jenkins \& Brand 2001). In the future, returning to the study area for continued replicate surveys over weeks or months will provide a time series that can inform on the recovery of local scallop communities after fishing disturbance.

\section{ACKNOWLEDGMENTS}

This project was funded by the NOAA Research Set-Aside Program (award number: NA14NMF4540073). The authors are indebted to the skilled captains and crew of the FV Christian and Alexa: Co-captain K. Ochse, co-caption A. Ochse, R. Adams, B. Young, D. Crosson, M. Kasserty and A. Ochse III.; V. Schmidt, for AUV data processing and field assistance; H. Brown for field assistance and development of the scallop image analysis system, the members of the VIMS research group who assisted in field and analysis efforts: S. Roman and J. Bergeron; D. Hart for valuable input throughout the project; C. Duval, T. Metz, K. Haulsee, and L. Morgan for assistance with fieldwork and side-scan sonar processing; and the image annotation team: M. Struble, I. Combs, L. Zodl, A. Halbruner, E. Ruhl, H. Kunz, L. Morgan, J. Douthit, S. Gangrade, N. Musacchio, S. Roman, A. Kaiser, A. Cabot, and J. Walker.

\section{LITERATURE CITED}

Armstrong, R. A., H. Singh, J. Torres, R. S. Nemeth, A. Can, C. Roman, R. Eustice, L. Riggs \& G. Garcia-Moliner. 2006. Characterizing the deep insular shelf coral reef habitat of the Hind Bank marine conservation district (US Virgin Islands) using the Seabed autonomous underwater vehicle. Cont. Shelf Res. 26:194-205.

Bates, D., M. Maechler, B. Bolker \& S. Walker. 2015. Fitting linear mixed-effects models using lme4. J. Stat. Softw. 67:1-48.

Bernstein, B. B. \& J. Zalinski. 1983. An optimum sampling design and power tests for environmental biologists. J. Environ. Manage. 16:3543.

Bewley, M., A. Friedman, R. Ferrari, N. Hill, R. Hovey, N. Barrett, O. Pizarro, W. Figueira, L. Meyer, R. Babcock, L. Bellchambers, M. Byrne \& S. B. Williams. 2015. Australian sea-floor survey data, with images and expert annotations. Sci. Data 2:1-12.

Bouguet, J.-Y. 2004. Camera calibration toolbox for Matlab. Available at: http://www.vision.caltech.edu/bouguetj/calib_doc/.

Bourne, N. 1964. Scallops and the offshore fishery of the Maritime Provinces. Fish. Res. Board Canada 145:1-60.

Bremec, C. S., M. L. Lasta \& D. Hernández. 2004. Survival of Patagonian scallop (Zygochlamys patagonica, King and Broderip, 1832) after the size selection process on commercial fishing vessels. Fish. Res. 66:49-52.

Britton, J. C. \& B. Morton. 1994. Marine carrion and scavengers. Oceanogr. Mar. Biol. Annu. Rev. 32:369-434.

Broadhurst, M. K., P. Suuronen \& A. Hulme. 2006. Estimating collateral mortality from towed fishing gear. Fish Fish. 7:180-218.

Caddy, J. F. 1968. Underwater observations on scallop (Placopecten magellanicus) behaviour and drag efficiency. J. Fish. Board Canada 25:2123-2141.

Caddy, J. F. 1973. Underwater observations on tracks of dredges and trawls and some effects of dredging on a scallop ground. Can. J. Fish. Aquat. Sci. 30:173-180.

Caddy, J. F. 1989. A perspective on the population dynamics and assessment of scallop fisheries, with special reference to the sea scallop, Placopecten magellanicus Gmelin. In: Caddy, J. F., editor. Marine invertebrate fisheries: their assessment and management. New York, NY: Wiley. pp. 559-589.

Collie, J. S., G. A. Escanero \& P. C. Valentine. 1997. Effects of bottom fishing on the benthic megafauna of Georges Bank. Mar. Ecol. Prog. Ser. 155:159-172.

de Groot, S. J. 1984. The impact of bottom trawling on benthic fauna of the North Sea. Ocean Manag. 9:177-190.

Dickie, L. M. 1958. Effects of high temperature on survival of the giant scallop. Can. J. Fish. Aquat. Sci. 15:1189-1211.

Dickie, L. M. \& J. C. Medcof. 1963. Causes of mass mortalities of scallops (Placopecten magellanicus) in the southwestern Gulf of St. Lawrence. J. Fish. Board Canada 20:451-482.

Downes, B., L. Barmuta, P. Fairweather, D. Faith, M. Keough, P. Lake, B. Mapstone \& G. Quinn. 2002. Monitoring ecological impacts: concepts and practice in flowing waters. Cambridge, UK: Cambridge University Press. 434 pp.

Fernandes, P. G., A. S. Brierley, E. J. Simmonds, N. W. Millard, S. D. McPhail, F. Armstrong, P. Stevenson \& M. Squires. 2000. Addendum: fish do not avoid survey vessels. Nature 407:152.

Fernandes, P. G., P. Stevenson, A. S. Brierley, F. Armstrong \& E. J. Simmonds. 2003. Autonomous underwater vehicles: future platforms for fisheries acoustics. ICES J. Mar. Sci. 60:684-691.

Forrest, A. L., M. E. Wittman, V. Schmidt, N. A. Raineault, A. Hamilton, W. Pike, S. G. Schladow, J. E. Reuter, B. E. Laval \& A. C. Trembanis. 2012. Quantitative assessment of invasive species in lacustrine environments through benthic imagery analysis. Limnol. Oceanogr. Methods 10:65-74.

Gallagher, S. 2014. The development of HabCam: the habitat mapping camera system. Undersea imaging workshop, Red Bank, NJ. 9 pp.

Gedamke, T., W. D. DuPaul \& J. M. Hoenig. 2004. A spatially explicit open-ocean DeLury analysis to estimate gear efficiency in the dredge fishery for sea scallop Placopecten magellanicus. N. Am. J. Fish. Manage. 24:335-351.

Gedamke, T., W. D. DuPaul \& J. M. Hoenig. 2005. Index-removal estimates of dredge efficiency for sea scallops on Georges Bank. $N$. Am. J. Fish. Manage. 25:1122-1129.

Grasmueck, M., G. P. Eberli, D. A. Viggiano, T. Correa, G. Rathwell \& J. Luo. 2006. Autonomous underwater vehicle (AUV) mapping reveals coral mound distribution, morphology, and oceanography in deep water of the Straits of Florida. Geophys. Res. Lett. 33: L23616.

Hart, D. R. 2003. Yield- and biomass-per-recruit analysis for rotational fisheries, with an application to the Atlantic sea scallop (Placopecten magellanicus). Fish Bull. 101:44-57.

Hart, D. R. 2013. Quantifying the tradeoff between precaution and yield in fishery reference points. ICES J. Mar. Sci. 70:591-603.

Hart, D. R. \& P. J. Rago. 2006. Long-term dynamics of U.S. Atlantic sea scallop Placopecten magellanicus populations. N. Am. J. Fish. Manage. 26:490-501.

Jenkins, S. R. \& A. R. Brand. 2001. The effect of dredge capture on the escape response of the great scallop, Pecten maximus (L.): implications for the survival of undersized discards. J. Exp. Mar. Biol. Ecol. 266:33-50.

Lamarche, G., A. R. Orpin, J. S. Mitchell \& A. Pallentin. 2016. Benthic habitat mapping. In: Clark, M. R., M. Consalvey \& A. A. Rowden, editors. Biological sampling in the deep sea. Chichester, UK: John Wiley \& Sons. pp. $80-102$.

Link, J. 2005. The effects of area closures on Georges Bank. Am. Fish. Soc. Symp. 41:345-368.

McLoughlin, R. J., P. C. Young, R. B. Martin \& J. Parslow. 1991. The Australian scallop dredge: estimates of catching efficiency and associated indirect fishing mortality. Fish. Res. 11:1-24. 
Medcof, J. C. \& N. Bourne. 1964. Causes of mortality of the sea scallop, Placopecten magellanicus. In: Proceedings of the National Shellfisheries Association. pp. 33-50.

Minchin, D., H. Skjaeggestad, G. A. Haugum \& Ø. Strand. 2000. Righting and recessing ability of wild and naive cultivated scallops. Aquacult. Res. 31:473-474.

Murawski, S. A. \& F. M. Serchuk. 1989. Environmental effects of offshore dredge fisheries for bivalves. ICES CM 1989/K27. 12 pp.

Myers, R. A., S. D. Fuller \& D. G. Kehler. 2000. A fisheries management strategy robust to ignorance: rotational harvest in the presence of indirect fishing mortality. Can. J. Fish. Aquat. Sci. 57:2357-2362.

Naidu, K. S. 1988. Estimating mortality rates in the Iceland scallop, Chlamys islandica (O. F. Müller). J. Shellfish Res. 7:61-71.

NEFSC. 2004. 39th Northeast Regional Stock Assessment Workshop (39th SAW): Assessment Report. Northeast Fisheries Science Center Reference Document 04-10b. pp. 87-211.

NEFSC. 2014. 59th Northeast Regional Stock Assessment Workshop (59th SAW): Assessment Report. Northeast Fisheries Science Center Reference Document 14-09. pp. 483-782.

NMFS. 2008. Fisheries of the United States 2007. Current fishery statistics no. 2007. National Marine Fishery Service, NOAA. Silver Spring, MD. Available at: https://www.st.nmfs.noaa.gov/Assets/ commercial/fus/fus07/fus_2007.pdf.

NMFS. 2009. Fisheries of the United States 2008. Current fishery statistics no. 2008. Silver Spring, MD: National Marine Fishery Service, NOAA. Available at: https://www.st.nmfs.noaa.gov/ Assets/commercial/fus/fus08/fus_2008.pdf.

NMFS. 2010. Fisheries of the United States 2009. Current fishery statistics no. 2009. Silver Spring, MD: National Marine Fishery Service, NOAA. Available at: https://www.st.nmfs.noaa.gov/ Assets/commercial/fus/fus09/fus_2009.pdf.

NMFS. 2011. Fisheries of the United States 2010. Current fishery statistics no. 2010. Silver Spring, MD: National Marine Fishery Service, NOAA. Available at: https://www.st.nmfs.noaa.gov/ Assets/commercial/fus/fus10/FUS_2010.pdf.

NMFS. 2012. Fisheries of the United States 2011. Current fishery statistics no. 2011. Silver Spring, MD: National Marine Fishery Service, NOAA. Available at: https://www.st.nmfs.noaa.gov/ Assets/commercial/fus/fus11/FUS2011.pdf.

NMFS. 2013. Fisheries of the United States 2012. Current fishery statistics no. 2012. Silver Spring, MD: National Marine Fishery Service, NOAA. Available at: https://www.st.nmfs.noaa.gov/ Assets/commercial/fus/fus12/FUS2012.pdf.

NMFS. 2014. Fisheries of the United States 2013. Current fishery statistics no. 2013. Silver Spring, MD: National Marine Fishery Service, NOAA. Available at: https://www.st.nmfs.noaa.gov/ Assets/commercial/fus/fus13/FUS2013.pdf.

NMFS. 2015. Fisheries of the United States 2014. Current fishery statistics no. 2014. Silver Spring, MD: National Marine Fishery Service, NOAA. Available at: https://www.st.nmfs.noaa.gov/ Assets/commercial/fus/fus14/documents/FUS2014.pdf.

NMFS. 2016. Fisheries of the United States 2015. Current fishery statistics no. 2015. Silver Spring, MD: National Marine Fishery Service, NOAA. Available at: https://www.st.nmfs.noaa.gov/ Assets/commercial/fus/fus15/documents/FUS2015.pdf.

Patterson, M., T. Hiller \& A. Trembanis. 2008. Exploring coral reef sustainability. Hydro Int. 12:14-19.

Quintero, F. M. 1996. Contrast autostretch 1.06: image filter plug-in for the GIMP image manipulation program. Available at: http://www.rpi.edu/dept/acm/packages/gimp/gimp-1.2.3/plug-ins common/c_astretch.c.

R Core Team. 2016. R: a language and environment for statistical computing. Vienna, Austria: R Foundation for Statistical Computing.

Raineault, N. A., A. C. Trembanis \& D. C. Miller. 2012. Mapping benthic habitats in Delaware Bay and the coastal Atlantic: acoustic techniques provide greater coverage and high resolution in complex, shallow-water environments. Estuaries Coasts 35:682-699.

Rankey, E. C. \& D. F. Doolittle. 2012. Geomorphology of carbonate platform-marginal uppermost slopes: insights from a Holocene analogue, Little Bahama Bank, Bahamas. Sedimentology 59:21462171.

Seiler, J., A. Friedman, D. Steinberg, N. Barrett, A. Williams \& N. J. Holbrook. 2012. Image-based continental shelf habitat mapping using novel automated data extraction techniques. Cont. Shelf Res. 45:87-97.

Singh, W., E. B. Örnólfsdóttir \& G. Stefansson. 2013. A camera-based autonomous underwater vehicle sampling approach to quantify scallop abundance. J. Shellfish Res. 32:725-732.

Singh, W., E. B. Örnólfsdóttir \& G. Stefansson. 2014. A small-scale comparison of Iceland scallop size distributions obtained from a camera based autonomous underwater vehicle and dredge survey. PLoS One 9:e109369.

Smith, E. P., D. R. Orvos \& J. Cairns. 1993. Impact assessment using the before-after-control-impact (BACI) model: concerns and comments. Can. J. Fish. Aquat. Sci. 50:627-637.

Stewart-Oaten, A., W. W. Murdoch \& K. R. Parker. 1986. Environmental impact assessment: "pseudoreplication" in time? Ecology 67:929-940.

Stokesbury, K. D. 2002. Estimation of sea scallop abundance in closed areas of Georges Bank, USA. Trans. Am. Fish. Soc. 131:1081-1092.

Taylor, R., N. Vine, A. York, S. Lerner, D. Hart, J. Howland, L. Prasad, L. Mayer \& S. Gallager. 2008. Evolution of a benthic imaging system from a towed camera to an automated habitat characterization system. Oceans 2008:1-7.

Trembanis, A. C., A. L. Forrest, B. M. Keller \& M. R. Patterson. 2017. Mesophotic coral ecosystems: a geoacoustically derived proxy for habitat and relative diversity for the leeward shelf of Bonaire, Dutch Caribbean. Front. Mater. Sci. 4:51.

Underwood, A. J. 1993. The mechanics of spatially replicated sampling programmes to detect environmental impacts in a variable world. Austral Ecol. 18:99-116.

Vining, R. 1978. Final environmental impact statement for the commercial harvesting of subtidal hardshell clams with a hydraulic escalator shellfish harvester. Olympia, WA: State of Washington, Department of Natural Resources. 57 pp.

Walker, J. 2013. Abundance and size of the sea scallop population in the Mid-Atlantic Bight. MS thesis, University of Delaware. 292 pp.

Walker, J. H., A. C. Trembanis \& D. C. Miller. 2016. Assessing the use of a camera system within an autonomous underwater vehicle for monitoring the distribution and density of sea scallops (Placopecten magellanicus) in the Mid-Atlantic Bight. Fish Bull. 114:261-273.

Weinhaus, F. 2007. Retinex. Available at: http://www.fmwconcepts. com/imagemagick/retinex/.

Yochum, N. \& W. D. Dupaul. 2008. Size-selectivity of the northwest Atlantic sea scallop (Placopecten magellanicus) dredge. J. Shellfish Res. 27:265-271. 